\title{
Experiences and Results from Cochlear Implantation in Patients with Long Duration of Deafness
}

\author{
Karin Lundin ${ }^{a, b} \quad$ Fredrik Stillesjö $^{a, b}$ Helge Rask-Andersen ${ }^{a, b}$ \\ a Section of Otolaryngology, Uppsala University Hospital, and ${ }^{\mathrm{b}}$ Department of Surgical \\ Sciences, Uppsala University, Uppsala, Sweden
}

Key Words

Cochlear implants · Long-time deafness

\begin{abstract}
Objective: The aim of the present study was to gauge factors that influence the outcome of cochlear implants (CI) in patients who have been deaf for an extended period. Patients and Methods: Twelve adult cases (13 ears) were operated on at the CI unit in Uppsala during the period of 2002-2013. These patients had a deafness duration ranging between 20 and 72 years in the implanted ear and severe to profound hearing loss or deafness in the other ear. Data concerning pre- and postoperative speech perception, deafness duration, hearing/deafness duration in the contralateral ear, age at implantation, intraoperative electrophysiological measurements, cause of deafness, and user status were collected. Results: Eleven of 12 patients (13 ears) benefitted from CI treatment. Conclusion: The overall hearing experience, deafness duration, and age at onset of deafness are important issues to consider prior to CI.
\end{abstract}

(C) 2014 S. Karger AG, Basel

\section{Introduction}

Cochlear implants (CI) are currently widely accepted as treatment for patients with severe bilateral hearing loss. Recently, the indications for CI have been widened to include patients with more residual hearing, single-sided deafness, and asymmetric hearing loss and even those with long-time deafness. In particular, deafness duration in the ear to be implanted has been suggested as a main predictive factor for CI outcome [Holden et al., 2013; UK Cochlear Implant Study Group, 2004]. Boisvert et al. [2012a] noted that many studies have focused on 
Lundin et al.: Experiences and Results from Cochlear Implantation in Patients with
Long Duration of Deafness

deafness duration in the implanted ear only. They suggested that this assumption may be appropriate in cases with symmetric hearing loss but not for asymmetric hearing loss.

Other studies [Boisvert et al., 2011, 2012a, b; Friedland at al., 2003; Távora-Vieira et al., 2013] have shown that it is the individual's overall auditory experience, not ear-specific, that is the best predictor of performance with CI. Gomaa et al. [2003] used deafness duration and preoperative sentence recognition measured using the Central Institute of Deafness (CID) sentence test score and defined a nonlinear term [Duration/ $(1+$ CID $)]$, which improved the correlation coefficient for the prediction of the CI outcome. Moon et al. [2013] found that age at implantation, age at onset of deafness, and duration of deafness negatively affected the CI outcome and that the age at onset of deafness was the most important factor.

A controversial issue is the negligible impact of the number of residual spiral ganglion cells [Khan et al., 2005]. They found that the total spiral ganglion cell counts did not significantly correlate with $\mathrm{CI}$ speech perception word scores for the 15 examined subjects; they considered it unlikely that the number of residual spiral ganglion cells is irrelevant to the determination of word recognition following cochlear implantation. They stated that there must be other clinical variables that play important roles in determining CI success.

We found that adult patients with postlingual deafness and maintained speech memory can perform remarkably well with $\mathrm{CI}$ even after a long period of profound hearing loss or deafness. In addition, patients with peri- and prelingual hearing deficiencies can benefit greatly from CI. A clinical dilemma is determining when to dissuade patients from CI. Here, we present $\mathrm{CI}$ outcomes from 12 adult cases with a deafness durations ranging between 20 and 72 years in the implanted ear. These patients had severe to profound hearing loss or deafness in the other ear and were operated on at the CI unit in Uppsala between 2002 and 2013. The aim of this study was to investigate the influencing factors that predict CI outcome for these patients.

\section{Patients and Methods}

The present study is retrospective and based on patient archives and files. Data on preand postoperative speech perception, deafness duration in the CI ear, hearing situation/ deafness duration in the contralateral ear, preoperative pure-tone average (PTA) in the contralateral and $\mathrm{CI}$ ear, age at implantation, results of intraoperative electrophysiological measurements [i.e., electrical Stapedius Reflex Thresholds (eSRT), Neural Response Telemetry (NRT; Cochlear, Lane Cove, N.S.W., Australia), Auditory Response Telemetry (ART; MedEl, Innsbruck, Austria), and electrical Auditory Brainstem Response (eABR)], cause of deafness, and whether the patient was a user were collected.

\section{Device Description and Fitting}

An implant from Cochlear [CI24RE(CA), CI422, or CI512] was used in 8 patients (9 ears), and an implant from MedEl (C40+, Concerto FLEX 28, or Concerto STD) was used in 4 patients. The patients were fitted 3-4 weeks postoperatively with a CI processor from Cochlear (Freedom or Nucleus5) or a processor from MedEl (Tempo+ or Opus2). The patients had four appointments with the $\mathrm{CI}$ team at the clinic for fitting, evaluation, and training during the first 2 weeks and then at $1,3,6$, and 12 months.

\section{Hearing Evaluation}

Preoperative PTA thresholds for $0.5,1,2$, and $4 \mathrm{kHz}$ were calculated. Phonetically balanced words (MS) [Svensk Talaudiometri; C-A Tegnér AB, 1998] were used to test speech perception. This test was performed in a sound-treated booth in free field at $65 \mathrm{~dB}$ sound 
pressure level (SPL) with the loud speaker at $0^{\circ}$. Preoperative best-aided MS-word scores and postoperative MS-word scores with CI were analyzed. Speech perception data were collected at 6 months or 1 year after the operation.

Patients were divided in three groups for analyses. Group 1 consisted of patients who were also deaf in the contralateral ear. Group 2 used a hearing aid (HA) in the contralateral ear. Group 3 included patients with severe peri- or prelingual hearing loss. A linear regression analysis was performed comparing deafness duration and hearing experience with postoperative performance. In addition, hearing experience divided by age at implantation (percentage of hearing years in life) was related to postoperative performance. We also analyzed the relationship between preoperative bilateral hearing and postoperative performance. The deafness duration was defined as the time in years since the sudden loss of hearing or, in progressive cases, the time in years since they were unable to benefit from HAs.

\section{Patients}

Twelve adult patients, 8 females and 4 males (13 implanted ears) with a minimum deafness duration of 20 years in the implanted ear (mean 40 years, range 20-72) were evaluated. The age at implantation varied between 39-80 years (mean 58). The patients underwent CI surgery between 2002 and 2013. The preoperative PTA in the implanted ears were $\geq 110$ $\mathrm{dB}$ normal hearing level (nHL), and the MS scores were $0 \%$ for all patients. The patient demographics are summarized in table 1.

\section{Results}

Six to 12 months after surgery, 6 patients had open-set speech perception (MS-words) in the CI ear. For bisyllabic words, 7 patients had open-speech understanding. One patient was not evaluated at 6 months. The average MS-word score among the full time users was $26 \%$ (range 0-64, $\mathrm{n}=10$ ). Among those with open-set MS-word discrimination, the mean score was 39\% (range 22-64, $n=6$ ). The deafness duration in those 6 patients with MS-word speech perception varied between 20-47 years. Two cases with bilateral deafness for 22 (No. 6, ear 1) and 20 (No. 3) years prior to implantation (age at onset of deafness 17 and 25 years) had postoperative MS-word scores of 40 and 56\%. Patient No. 6 (ear 1) had hearing loss from birth. Both patients were able to use the telephone after surgery.

Patient No. 1 had deafness duration of 39 years and scored $22 \%$ on the MS-word test 1 year after the CI surgery (56\% bisyllabic words, $93 \%$ on informal bilateral auditory-only sentence test compared to $0 \%$ before surgery). The patient had a progressive sensorineural hearing loss in the contralateral ear and was also exposed to radiation therapy due to a pituitary tumor. He had a radical cavity and became deaf in the CI-operated ear after chronic ear surgery 39 years before. Patient No. 4 had a deafness duration of 47 years and scored $24 \%$ on the MS-word test after CI. Three patients used the implant mainly to perceive environmental sounds and improve lip reading (Nos. 5, 8, and 9). Patient No. 5 experienced 50 years of deafness in the implanted ear and perceived only nonauditory sensations from the implant. He used HA in the contralateral ear for 44 years. Hearing loss started early in the CI-operated ear (age 14 years). This patient was the only one who had no electrophysiological responses intraoperatively. The MS-word score was 10\% bilaterally before surgery. Patient No. 8 had severe prelingual hearing loss with impaired speech production, and patient No. 9 had bilateral hearing loss for 56 years prior to CI surgery. Patient No. 9 experienced tinnitus during implant use but used it part time to improve lip reading. One patient with 72 years of bilateral deafness (No.2) experienced severe tinnitus from implant use and became a nonuser. Another patient with 37 years of deafness in the implanted ear (No. 6, ear 2) had a previous 
Table 1. Age at implantation, deafness duration, hearing in contralateral ear and age at onset of deafness

\begin{tabular}{|c|c|c|c|c|}
\hline $\begin{array}{l}\text { Patient } \\
\text { No. }\end{array}$ & $\begin{array}{l}\text { Age at } \\
\text { implanta- } \\
\text { tion, years }\end{array}$ & $\begin{array}{l}\text { Deafness } \\
\text { duration in the } \\
\text { CI ear, years }\end{array}$ & Hearing in the nonimplanted ear & $\begin{array}{l}\text { Age at onset } \\
\text { of deafness } \\
\text { in the CI ear, } \\
\text { years }\end{array}$ \\
\hline \multicolumn{5}{|c|}{ Group 1: deaf in the contralateral ear } \\
\hline 2 & 80 & 72 & Deaf for 72 years & 8 \\
\hline 3 & 45 & 20 & Deaf for 36 years & 25 \\
\hline 6, ear 1 & 39 & 22 & Deaf for 35 years & 17 \\
\hline 6 , ear 2 & 41 & 37 & Deaf for 22 years, CI for 2 years & 4 \\
\hline 9 & 64 & 56 & Deaf for 56 years & 8 \\
\hline \multicolumn{5}{|c|}{ Group 2: HA in the contralateral ear } \\
\hline 1 & 72 & 39 & $\begin{array}{l}\text { HA user for } 30 \text { years } \\
\text { PTA: } 86.3 \mathrm{~dB} \text { nHL } \\
\text { MS } 4 \% \text { at } 80 \mathrm{~dB} \text { SPL (bilateral MS 0\%) }\end{array}$ & 33 \\
\hline 4 & 65 & 47 & $\begin{array}{l}\text { HA user for } 15 \text { years } \\
\text { PTA: } 91.3 \mathrm{~dB} \text { nHL } \\
\text { MS } 28 \% \text { at } 80 \mathrm{~dB} \text { SPL (bilateral MS 18\%) }\end{array}$ & 18 \\
\hline 5 & 64 & 50 & $\begin{array}{l}\text { HA user for } 44 \text { years } \\
\text { PTA: } 0.5 \mathrm{kHz}(80 \mathrm{~dB} \text { nHL) and } 1 \mathrm{kHz}(110 \mathrm{~dB} \mathrm{nHL}) \\
\text { MS } 18 \% \text { at } 80 \mathrm{~dB} \text { SPL (bilateral MS } 10 \%)\end{array}$ & 14 \\
\hline 10 & 54 & 30 & $\begin{array}{l}\text { HA user for } 30 \text { years PTA: } 93.5 \mathrm{~dB} \text { nHL } \\
\text { MS } 56 \% \text { at } 80 \mathrm{~dB} \text { SPL (bilateral MS 74\%) }\end{array}$ & 24 \\
\hline 11 & 69 & 31 & $\begin{array}{l}\text { HA user for } 10 \text { years PTA: } 91.3 \mathrm{~dB} \text { nHL } \\
\text { MS } 12 \% \text { at } 75 \mathrm{~dB} \text { SPL (bilateral not measured) }\end{array}$ & 38 \\
\hline 12 & 64 & 31 & $\begin{array}{l}\text { HA user for } 27 \text { years PTA: } 85 \mathrm{~dB} \text { nHL } \\
\text { MS } 50 \% \text { at } 70 \mathrm{~dB} \text { SPL (bilateral not measured) }\end{array}$ & 33 \\
\hline \multicolumn{5}{|c|}{ Group 3: bilateral peri- or prelingual hearing loss } \\
\hline 7 & 47 & $\begin{array}{l}\text { Perilingual hearing } \\
\text { loss, severe hearing } \\
\text { loss for } 35 \text { years } \\
\text { PTA: >110 dB nHL }\end{array}$ & $\begin{array}{l}\text { HA user for } 35 \text { years PTA: } 0.5 \mathrm{kHz}(95 \mathrm{~dB} \mathrm{nHL}) \text {, } \\
1 \mathrm{kHz}(115 \mathrm{~dB} \text { nHL) and } 2 \mathrm{kHz}(110 \mathrm{~dB} \text { nHL) }\end{array}$ & - \\
\hline 8 & 49 & $\begin{array}{l}\text { Severe prelingual } \\
\text { hearing loss } \\
\text { PTA: }>110 \mathrm{~dB} \text { nHL }\end{array}$ & $\begin{array}{l}\text { HA user for } 49 \text { years PTA: } 0.5 \mathrm{kHz}(95 \mathrm{~dB} \mathrm{nHL}) \text {, } \\
1 \mathrm{kHz}(105 \mathrm{~dB} \mathrm{nHL}) \text { and } 2 \mathrm{kHz}(105 \mathrm{~dB} \mathrm{nHL})\end{array}$ & - \\
\hline
\end{tabular}

successful implantation in the contralateral ear and showed little motivation for the second implant and did not use it.

The 2 patients in group 3 with peri- or prelingual hearing loss (Nos. 7 and 8) benefited from the CIs and used them full time. Patient No. 7 scored $12 \%$ on the bisyllabic word test (table 2).

Postoperative speech perception, the cause of deafness, CI use, and intraoperative electrophysiological responses, including the subjective experiences of the patients, are summarized in table 2. A statistically significant correlation was found between the postoperative speech perception in the implanted ear and the deafness duration in the implanted ear in groups 1 and 2 ( $r=0.84, \mathrm{p}<0.01$, fig. 1 ). There was also a statistically significant positive correlation between the age at onset of deafness in the implanted ear and postoperative speech perception for group 1 ( $r=0.99, \mathrm{p}<0.05$, fig. 2 ). There was a statistically significant correlation between the postoperative speech perception in the implanted ear and the hearing experience divided by age at implantation (percentage of hearing years in life) for groups 1 and $2(r=0.80, p<0.01$, fig. 3). Additionally, there was a tendency for group 2 patients who had better bilateral preoperative word discrimination to have better word discrimination with the $\mathrm{CI}(\mathrm{r}=0.81, \mathrm{p}<0.1$, fig. 4). 

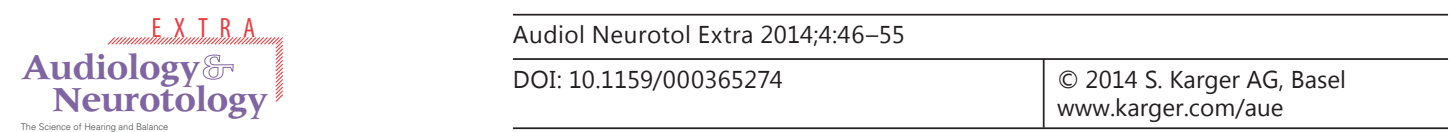

Lundin et al.: Experiences and Results from Cochlear Implantation in Patients with

Long Duration of Deafness

Table 2. Presence of intraoperative electrophysiological measurements, deafness duration, cause of deafness, postoperative speech perception and CI use

\begin{tabular}{lllllll}
\hline Patient & Intraop. eABR/ & Deafness & Cause of & Postop. & Patient comment & User \\
No. & eSRT/NRT- & duration in & deafness & MS in the CI & (Y/N/ \\
& ART (Y/N/ & the CI ear, & & ear only, $\%$ & part \\
& not measured) & years & & & time)
\end{tabular}

Group 1: deaf in the contralateral ear

$\begin{array}{lllll}2 & \text { Y/Y/Y } & 72 & \text { Meningitis } & - \\ & & & & \\ 3 & \text { Y/Y/Y } & 20 & \begin{array}{l}\text { Meningitis } \\ \text { and scarlatina }\end{array} & 58 \\ \text { 6, ear } 1 & \text { Not measured/ } & 22 & \text { Not known } & 40 \\ & \text { Y/Y } & & \text { Not known } & - \\ \text { 6, ear } 2 & \text { Y/Y/Y } & 37 & & \end{array}$

$9 \quad+\quad 56 \quad$ Meningitis

Gets hearing sensations from implant but no speech

$\mathrm{N}$ perception. In addition, gets severe tinnitus from implant use, and tinnitus is the reason for being a non user.

Feels much more confident and less tense after CI. Y Can manage basic telephone calls.

Satisfied with the CI. Listens to music with the CI. Y

Can use the telephone with 'known' speakers.

Struggles to get motivated to start using the second implant but decides 1 year postop. that she does not want to. Gets headache from implant use and describes the sound as vibrations.

Uses implant as a complement to lip reading. Gets Part tinnitus from implant use and is therefore a part time time user.

\section{Group 2: HA in the contralateral ear \\ $1 \quad$ Not measured/ 39 not measured/Y

$\begin{array}{lll}4 & \text { Not measured/ } & 47 \\ & \text { Y/Y } & \\ 5 & \text { N/N/N } & 50\end{array}$

10

Not measured/ 30 not measured/Y

11

$\mathrm{Y} / \mathrm{Y} / \mathrm{Y}$ 31

$\mathrm{Y} / \mathrm{Y} / \mathrm{Y}$ 31
Deaf after 22

cholesteatoma surgery

Recurring otitis media Recurring otitis media

Not known

64

Sudden

deafness

Deaf after otosclerosis surgery

24 24$$
-
$$

Recently fitted, not measured yet

Uses CI full time, feels it is a good compliment to HA. Y Problems with facial nerve stimulation due to high stimulation levels. Gets vertigo after CI that still troubles her after 1 year.

\begin{tabular}{ccc}
\hline $\begin{array}{c}\text { Group } \\
7\end{array}$ & Bilateral peri- or prelingual hearing loss \\
& $\mathrm{Y} / \mathrm{Y} / \mathrm{Y}$ & Perilingual \\
& hearing loss, \\
& severe hearing \\
& loss for 35 \\
& years; PTA: \\
& $>110 \mathrm{~dB} \mathrm{nHL}$ \\
& Severe \\
& prelingual \\
& hearing loss; \\
& PTA: \\
& $>110 \mathrm{~dB}$ nHL
\end{tabular}

Not measured

Not measured
New sounds popping up continuously. Happy with the CI. Has some troubles getting used to high frequency sounds. Reports that it is easier to talk to colleagues now. Works full time. Gets $12 \%$ on test with bisyllabic words in the CI ear.

Is very happy with the implant even though it is not able to measure on speech tests. Hears surrounding sounds and reports to love to hear the letter /s/. The hearing improves continuously. 
Lundin et al.: Experiences and Results from Cochlear Implantation in Patients with Long Duration of Deafness

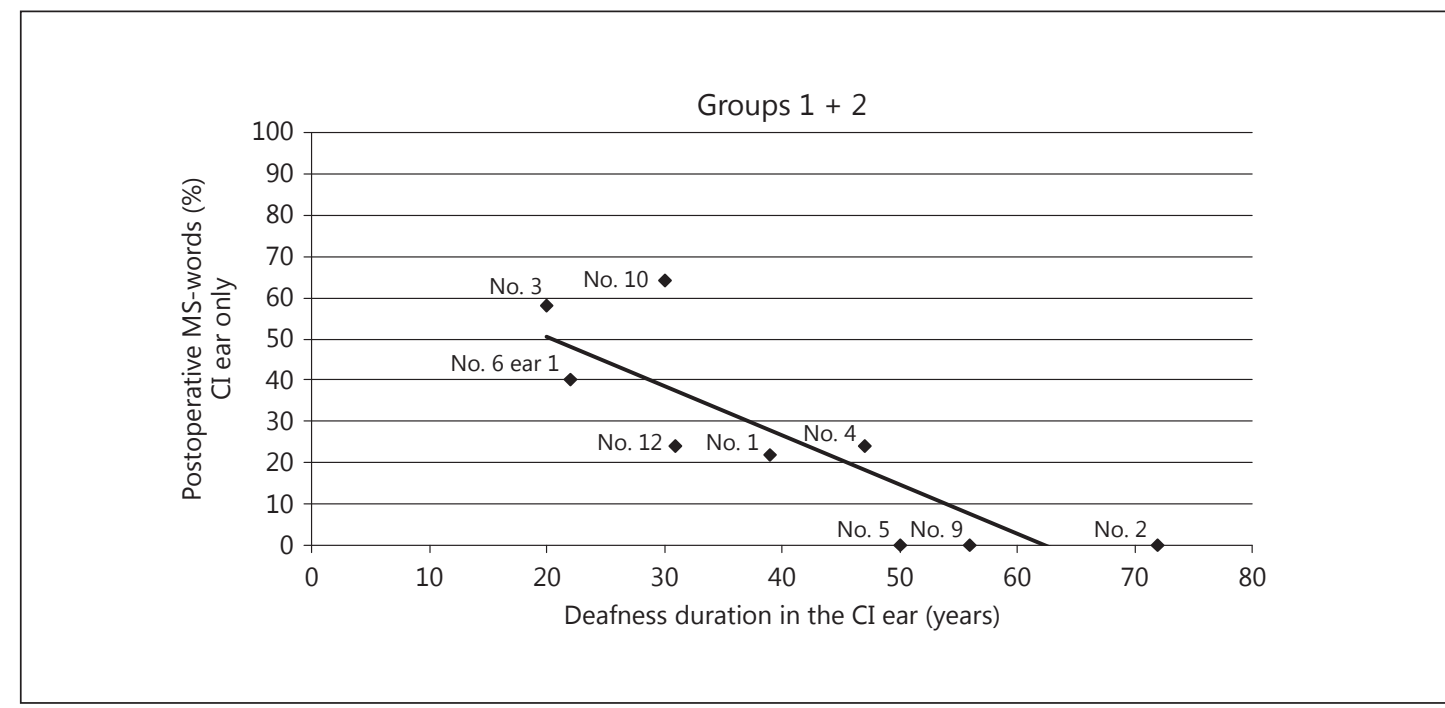

Fig. 1. Diagram showing the relationship between postoperative speech perception (MS-words) in the CI ear for groups 1 and 2 and deafness duration $(r=0.84, p<0.01)$.

Fig. 2. Diagram showing the relationship between postoperative speech perception (MS-words) in the CI ear for groups 1 and 2 and age at onset of deafness in the CI ear. The regression line is shown for group $1(\mathrm{r}=0.99, \mathrm{p}<0.05)$.

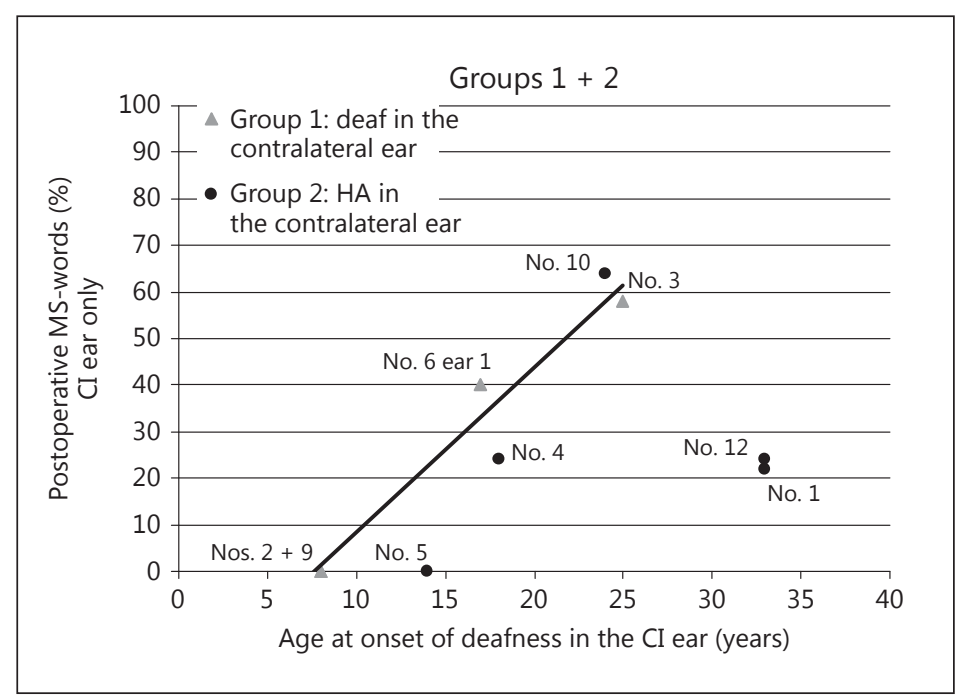

\section{Discussion}

Our results showed that there is a negative correlation between the deafness duration and the $\mathrm{CI}$ outcome (fig. 1). This means that patients with longer deafness durations did less well with CIs. However, our material included patients with both bilateral deafness and contralateral residual hearing. Therefore, conclusive interpretations are difficult to make because preserved contralateral hearing probably has a major impact on speech memory and intelligibility, which influences the CI outcome. In their study of $58 \mathrm{CI}$ patients with deafness durations in the implanted ear between 1 and 60 years (mean 12), Friedland et al. [2003] concluded that each year of additional deafness results in a loss of $1 \%$ in postoperative word recognition testing. Gomaa et al. [2003] found that each additional year in deafness yields a 
Lundin et al.: Experiences and Results from Cochlear Implantation in Patients with

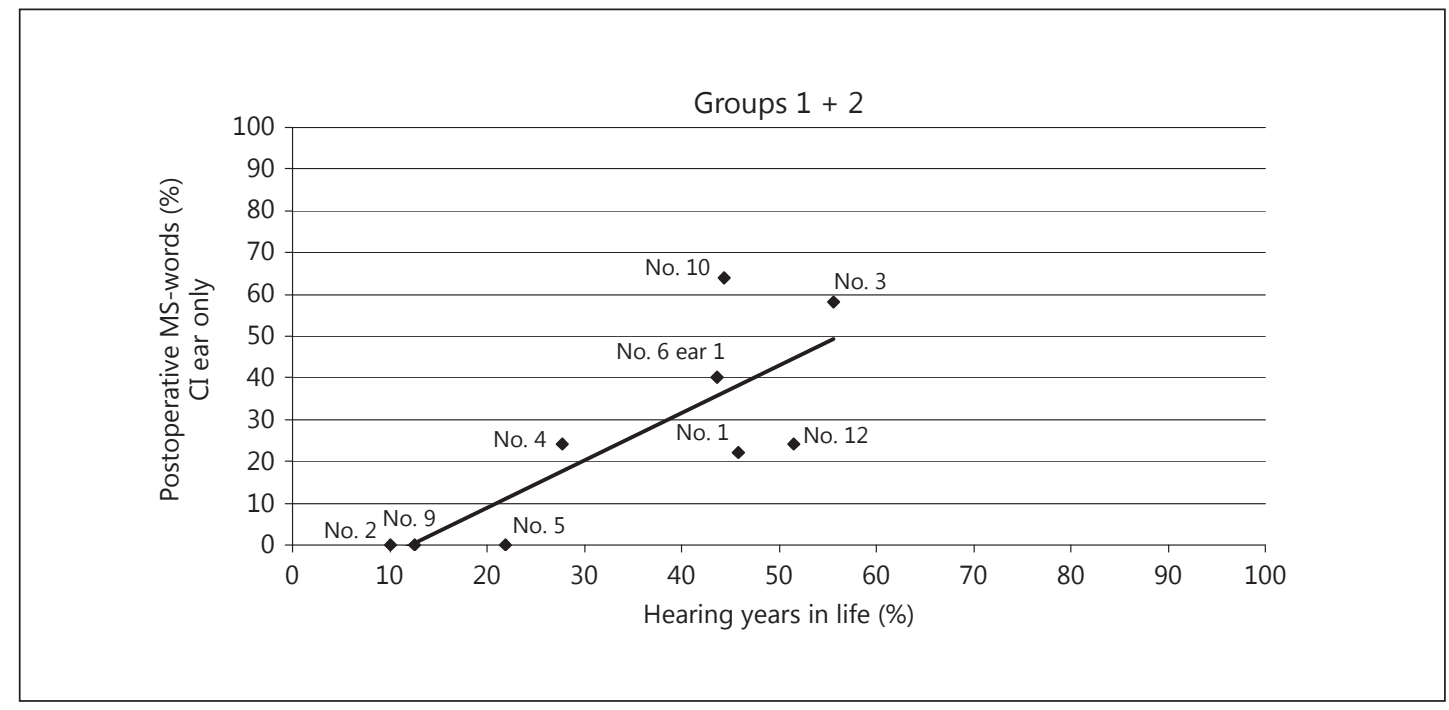

Fig. 3. Diagram showing the relationship between postoperative speech perception (MS-words) in the CI ear for groups 1 and 2 and age at onset of deafness in the CI ear divided by age at implantation $(r=0.80, p<0.01)$.

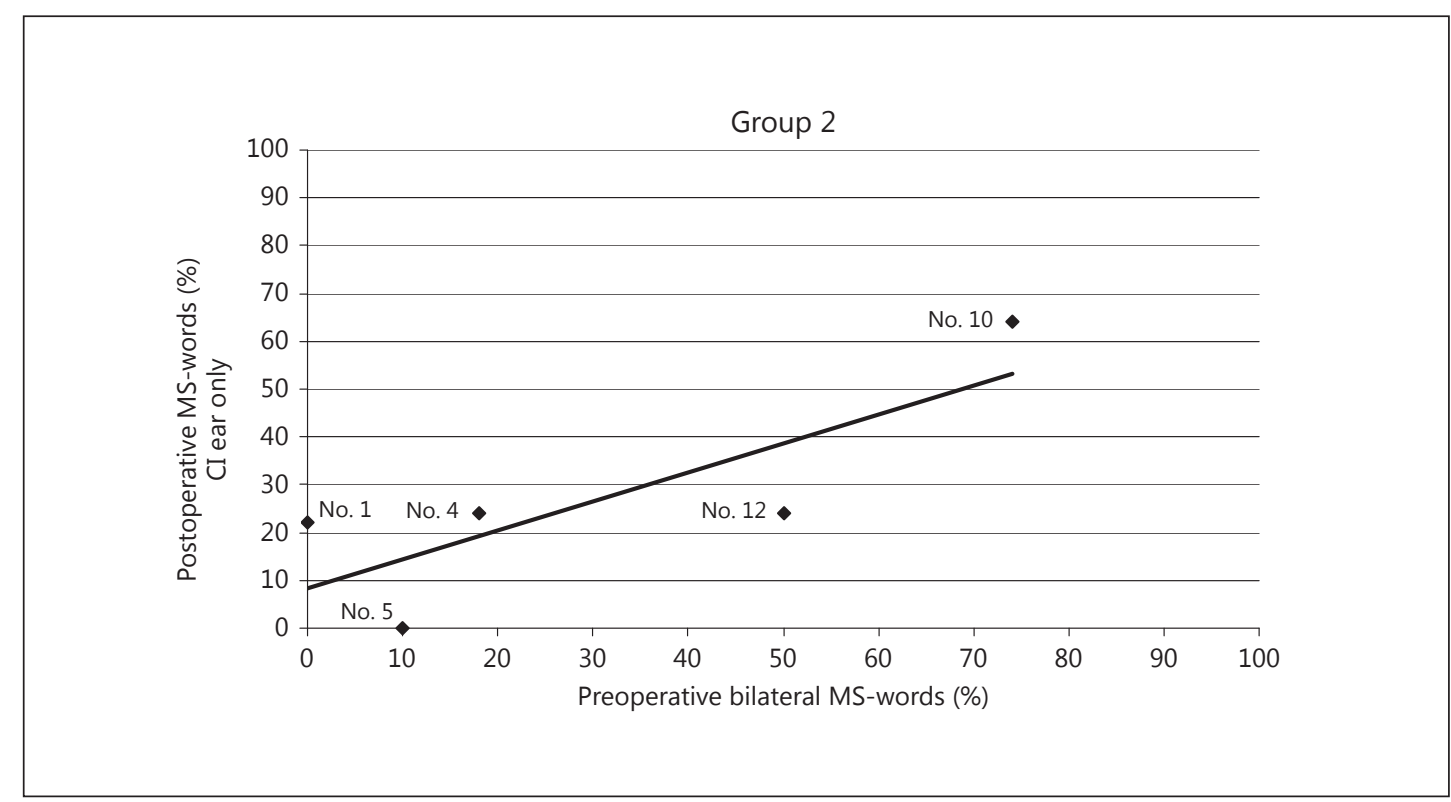

Fig. 4. Diagram showing the relationship between postoperative speech perception (MS-words) in the CI ear only and preoperative bilateral speech perception (MS-words) for group $2(r=0.81, p=0.099)$.

decrease of $0.7 \%$ in postoperative word perception. When analyzing groups 1 and 2 in the present study, we found similar results, i.e., every year of deafness resulted in a loss of approximately $1 \%$ (fig. 1).

Our results showed that patients with long-term bilateral deafness can achieve useful speech understanding results with a CI. Two outstanding cases are noted: one with bilateral deafness for 22 years (No. 6, ear 1) and one for 20 years (No. 3) prior to implantation. Both 
Lundin et al.: Experiences and Results from Cochlear Implantation in Patients with Long Duration of Deafness

patients had a long period of hearing experience before deafness (17 and 25 years) and were relatively young at the time of implantation (age 39 and 45 years), which could be the reason for the success (fig. 2, 3). Both of these patients had preserved speech memory even though one of the patients had impaired speech production. Amazingly, the patients could use the telephone. This result shows that auditory neurons are preserved and electrically excitable despite many years of inactivity [Liu et al., 2014]. The slow retrograde degeneration of the human auditory nerve following loss of auditory mechanoreceptors suggests that there are important biological differences between humans and animals. The resistance to degeneration has also been confirmed in histological studies [Linthicum and Fayad, 2009; Liu et al., 2013; Nadol, 1997; Teufert et al., 2006].

Our data combined with the findings by Friedland et al. [2003], Moon et al. [2013], and Boisvert et al. [2012a, b] imply that it is important to consider the age at the onset of deafness in patients with bilateral hearing loss. The auditory cortex needs to obtain a certain amount of qualified auditory information for a certain amount of years to create the necessary and stable associative couplings or 'hearing memories' to sense sounds and comprehend language. Moon et al. [2013] found that the age at implantation, the age at onset of deafness, and the duration of deafness negatively affected the $\mathrm{CI}$ outcome and that age at the onset of deafness was the most important factor. The cause of deafness and device type had no significant impact. They found a significant difference in the CI outcome when the deafness duration was more than 30 years, and when analyzing the factors that affect the outcomes of patients with duration of deafness exceeding 30 years, the age at the onset of deafness was the only important factor. Their results suggest that age at the onset of deafness should be considered as a critical factor. Patients who became deaf before the age of 13 years performed significantly worse. Our results corroborate these data. In this study, patients with long deafness durations ( $\geq 50$ years) in the $\mathrm{CI}$ ear and limited years of hearing experience ( $\leq 14$ years) did not perform as well as those with shorter periods of deafness and longer periods of hearing experience (fig. 1, 2). Our results show that patients with $\leq 22 \%$ of hearing years compared to age did not perform as well as the others (fig. 3). These results suggest that elderly patients with long periods of deafness can do better than their younger counterparts because it is the relative number of years of deafness that is important for CI outcome. An absolute limit was not possible to determine due to the small number of patients studied here. However, age at the onset of deafness and deafness duration are critical factors to consider.

Our results indicate that the better the patients' bilateral hearing was before $\mathrm{CI}$, the better the results (fig. 4). This result is in agreement with findings made by other investigators. Friedland et al. [2003] found that it is the overall auditory experience of the individual that is the best predictor of $\mathrm{CI}$ performance for postlingually deafened adults and that implantation in the worse performing ear does not predict poor CI performance. Boisvert et al. [2011] analyzed patients who were implanted in an ear with at least 15 years of severe or profound hearing loss. They found strong correlations between the CI outcome and the duration of significant bilateral hearing loss, percentage of lifetime of bilateral hearing loss, and the duration of stimulation before the bilateral hearing loss. No significant correlations were found between these factors when looking at the CI ear only. Távora-Vieira et al. [2013] examined the CI outcome in 5 adults with over 25 years of unilateral deafness. All patients had normal hearing or mild loss in the better ear. They showed that the duration of deafness is not the only important factor for the success of cochlear implantation in patients with postlingual unilateral deafness. They suggested that monaural auditory stimulation may be sufficient to maintain the integrity of the auditory pathways bilaterally. Boisvert et al. [2012a] showed that speech understanding in one ear can be enough to achieve a good CI outcome in the other ear, and they only identified the duration of significant bilateral hearing loss as a factor affecting the CI outcome. Boisvert et al. [2012b] determined if the CI outcome is influ- 
enced by the choice of the ear in patients who use HA in one ear and are deaf in the other ear. The surgeon may consider implanting in the completely deaf ear or the contralateral ear with residual hearing (HA ear). They found similar bilateral outcome after the CI for both groups even though the patients implanted in the HA ear performed significantly better when tested with the CI ear only. They suggested that there are few disadvantages to implanting in the lower performing ear. We agree that the surgeon may choose to implant in the lower performing ear despite the long period of complete deafness when residual hearing is present in the other ear. A pertinent neural population may exist in most cases, depending on the cause of deafness. In our experience, the outcome is mostly satisfactory, and the patient can use a combination of an HA and the CI after surgery. However, we found no statistically significant correlation between preoperative bilateral MS-word scores and CI outcome. Nevertheless, there was a positive trend between preoperative bilateral MS-word scores and CI outcomes even though the number of patients was small (fig. 4), which suggests that the status of the contralateral ear may play a significant role in the outcome.

Notably, patient No. 5 reported only nonauditory sensations and was the only one lacking intraoperative electrophysiological responses. This patient had limited auditory input from the contralateral ear, an early onset of deafness, and long deafness duration in the CI ear, decreasing speech memory. It is possible that the implantation was made in the nonoptimal ear. Two patients had tinnitus during implant use (Nos. 2 and 9). They both had long-term bilateral deafness (56 and 72 years) due to meningitis as well as an onset of deafness at a young age ( 8 years). These two patients are no typical CI candidates and were implanted for unusual reasons. Patients with meningitis are generally considered to have less favorable results. However, we do not rule out a positive outcome in this patient category, considering the positive results in patient No. 3 .

These findings and earlier reports suggest that it is the total hearing experience rather than the deafness duration in the $\mathrm{CI}$ ear alone that is the important factor for $\mathrm{CI}$ outcome in patients with long periods of deafness. Since it is the relative length of hearing prior to hearing loss that is important, it is crucial not to exclude elderly patients from CI surgery, even though deafness duration may have been long (fig. 3).

\section{Conclusion}

Even patients with extended deafness durations can achieve speech understanding and benefit from CIs. The important issues to consider are the overall hearing experience, deafness duration, and the age at onset of deafness. In this study, patients with long deafness duration ( $\geq 50$ years) and limited years of hearing experience ( $\leq 14$ years) did not perform as well as those with shorter deafness durations and longer periods with hearing experience. Our results suggest that the age at onset of deafness relative to current age should be considered. Careful preoperative counselling is necessary because outcomes may still be difficult to predict.

\section{Acknowledgement}

This study was possible through generous donations from Börje Runögård, Stockholm, Sweden. 


\section{Audiology \\ Neurotology}

\section{Disclosure Statement}

\section{The authors have no conflicts of interest to disclose.}

Extra 2014:4:46-55 (c) 2014 S. Karger AG, Basel www.karger.com/aue

Lundin et al.: Experiences and Results from Cochlear Implantation in Patients with Long Duration of Deafness

\section{References}

Boisvert I, McMahon CM, Dowell RC: Long-term monaural auditory deprivation and bilateral cochlear implants. Neuroreport 2012a;23:195-199.

Boisvert I, Lyxell B, Mäki-Torkko E, McMahon CM, Dowell RC: Choice of ear for cochlear implantation in adults with monaural sound-deprivation and unilateral hearing aid. Otol Neurotol 2012b;33:572-579.

Boisvert I, McMahon CM, Tremblay G, Lyxell B: Relative importance of monaural sound deprivation and bilateral significant hearing loss in predicting cochlear implantation outcomes. Ear Hear 2011;32:758-766.

Friedland DR, Venick HS, Niparko JK: Choice of ear for cochlear implantation: the effect of history and residual hearing on predicted postoperative performance. Otol Neurotol 2003;24:582-589.

Gomaa NA, Rubinstein JT, Lowder MW, Tyler RS, Gantz BJ: Residual speech perception and cochlear implant performance in postlingually deafened adults. Ear Hear 2003;24:539-544.

Holden LK, Finley CC, Firszt JB, Holden TA, Brenner C, Potts LG, Gotter BD, Vanderhoof SS, Mispagel K, Heydebrand G, Skinner MW: Factors affecting open-set word recognition in adults with cochlear implants. Ear Hear 2013; 34:342-360.

Khan AM, Handzel O, Burgess BJ, Damian D, Eddington DK, Nadol JB Jr: Is word recognition correlated with the number of surviving spiral ganglion cells and electrode insertion depth in human subjects with cochlear implants? Laryngoscope 2005;115:672-677.

Linthicum FH, Fayad JN: Spiral ganglion cell loss is unrelated to segmental cochlear sensory system degeneration in humans. Otol Neurotol 2009;30:418-422.

Liu W, Glueckert R, Linthicum FH, Rieger G, Blumer M, Bitsche M, Pechriggl E, Rask-Andersen H, Schrott-Fischer A: Possible role of gap junction intercellular channels and connexion 43 in satellite glial cells (SGCs) for preservation of human spiral ganglion neurons: a comparative study with clinical implications. Cell Tissue Res 2014; 355:267-278.

Moon IS, Park S, Kim H-N, Lee W-S, Kim SH, Kim JH, Choi JY: Is there a deafness duration limit for cochlear implants in post-lingual deaf adults? Acta Otolaryngol 2014;134:173-180.

Nadol JB: Patterns of neural degeneration in the human cochlea and auditory nerve: implications for cochlear implantation. Otolaryngol Head Neck Surg 1997;117:220-228.

Távora-Vieira D, Boisvert I, McMahon CM, Maric V, Rajan GP: Successful outcomes of cochlear implantation in longterm unilateral deafness: brain plasticity? Neuroreport 2013;24:724-729.

Teufert KB, Linthicum FH Jr, Connell SS: The effect of organ of corti loss on ganglion cell survival in humans. Otol Neurotol 2006;27:1146-1151.

-UK Cochlear Implant Study Group: Criteria of candidacy for unilateral cochlear implantation in postlingually deafened adults I: theory and measures of effectiveness. Ear Hear 2004;25:310-335. 